Journal of Counselor Practice, 11(1):34-54, 2020

DOI: $10.22229 / \mathrm{sch} 1112020$

Copyright (C) Ohio Counseling Association

\title{
With a Little Help from My Friends: School Counseling and University Outreach Center Partnerships
}

\author{
Angela Cameron ${ }^{1}$ \\ Youngstown State University \\ Jake J. Protivnak \\ Youngstown State University
}

School counselors need significant resources to meet student needs. Universities and counselor educators are often overlooked resources and partnerships for school counselors who can provide professional development, assist with research projects, grant writing, and program evaluation (Wright, 2012). A University Outreach Center (UOC) is a department located within a university that have mission to connect university faculty with community partners on projects where there are shared interests and benefits. UOCs specialize in coordinating faculty and community partnerships focused on grant writing and management, program development, needs assessment, program evaluation, and professional development. The purpose of this article is to provide an overview of the general structure of University Outreach Centers (UOCs), discuss the mutual benefits of school counselor-UOC partnerships, present a model for developing the partnership, share a case example, and review the legal, ethical, and relational issues.

\section{Keywords: School Counseling, University Outreach, Community Partnerships}

"Do more with less" is a message often implicitly received by school counselors and educational administrators. School counselors are challenged with increased student academic concerns and mental health issues, unfulfilled expectations by parents and

\footnotetext{
$1 \quad$ Correspondence may be sent to: Angela Cameron, Center for Human Services Development \& Adjunct Instructor, Counseling Program, Youngstown State University, Beeghly College of Education, Youngstown, OH 44555-0001, amcameron@ysu.edu, Phone: 330-941-3469/Fax: 330-941-2369.
} 
administrators, and unfunded initiatives by state legislators. While experiencing reduced funding, school counselors must advocate for their students and themselves to obtain resources to accomplish school counseling responsibilities. One possibility for school counselors to enhance their programs and services involves establishing mutually beneficial partnerships with professionals outside of their school. Cobia and Henderson (2007) encouraged school counselors to strengthen relationships with the community by including professionals from outside agencies with similar interest in the counseling services for school-aged children and their families. A school-community collaboration is effective in bridging needs within the school with services available through the community (Mellin, Belknap, Brodie, \& Sholes, 2015). A lack of school-community collaboration results in an isolated school and students without adequate resources to meet the competencies in academic, social/emotional, and career development areas. Walsh, Howard, and Buckley (1999) stated universities should be community partners with school counselors. While partnerships are common within teacher preparation and counselor preparation for the purpose of placing student's teacher candidates and school counseling interns, the opportunities beyond field placement are often unrealized.

School counselors, with the support of their administrators, are uniquely trained to establish relationships with students, understand barriers to their success, and provide interventions to promote their development. Relationships between school counselors and community resources are encouraged throughout the training of school counselors. The 2016 Council for Accreditation of Counseling and Related Educational Programs standards (CACREP, 2015, p. 33), requires that students learn "models of school-based collaboration and consultation" (G.1.d) and "roles in consultation with...postsecondary school personnel, 
and community agencies" (G.2.b). School counselors have expert knowledge and skills to create system wide programming to increase student success (Atici, 2014). When provided with appropriate resources and supportive partners, school counselors are able to create comprehensive school counseling programs, build community relationships, and address academic and non-academic barriers (Walsh, Howard, \& Buckley, 1999).

The availability of school counseling resources (e.g., staff, materials) are crucial for school counselors to accomplish their goals. Stone and Dahir (2006) recommended school counselors develop a 'community resource directory' that includes contact information for community agencies that offer support to school-aged students. Universities are types of agencies within a community that can provide professional development, assistance with research projects, grant writing, and program evaluation (Wright, 2012). There are numerous examples of successful university school partnerships with teacher education (Fleisher, Westfield \& Bank, 1990), nursing education (Kreulen, Bednarz, Wehrwein, \& Davis, 2008), special education (Buisson \& Salgo, 2012), and school counseling (Bryan \& Holcombe-McCoy, 2007; Castro-Atwater, 2013). Beyond field placement partnerships with various disciplines, the most common partnerships between schools and universities are after-school programs (Grineski, 2003; Mahoney, Levine, \& Hinga, 2010). The purpose of this article is to provide an overview of the structure of University Outreach Centers (UOCs), discuss the mutual benefits of school counselor-UOCs partnerships, present a model for developing the partnership, provide a case example, and the review the legal, ethical, and relational issues when negotiating a school-university relationship. 


\section{University Outreach Centers (UOCs)}

University Outreach Centers (UOC) is a department located on a university campus that works to connect faculty and the community on projects where there are shared interests and benefits. UOCs can have a variety of names (e.g., Center for Evaluation, Research, \& Professional Learning; Center for Community Planning and Development; Office of Outreach and Engagement; Community Relations and Engagement; Center for Campus and Community Engagement; Center for Community \& Civic Engagement, etc.). UOCs can be based within a university academic department (e.g., Department of Counseling, School Psychology, \& Educational Leadership) or as a standalone department reporting directly to a college dean or provost. The services provided by UOCs are not necessarily connected to the academic department or college where they are located (e.g., a center within the College of Education is not restricted to focus solely on partnerships with K-12 schools.). Services provided by UOCs vary based upon the needs of the local community, university faculty, and the abilities of the UOCs staff. UOCs must have knowledge about a variety of professional areas and typically have a diverse set of skills, backgrounds, and experiences related to community support and grant agency compliance requirements. As projects move forward, UOC staff must rely on the expertise of others (e.g., grant authors, school counselors, faculty, etc.). The projects completed by UOCs often include grant writing, grant management, needs assessment, program evaluation, strategic planning, and professional development. UOCs funding is typically on 'soft money' (i.e., funded by new or renewal grants), and the viability of the UOC is contingent upon continuing to receive grants. Consequently, there is a monetary incentive for UOCs 
to identify and establish new partnerships with schools and agencies in the community in order to sustain their operations.

University Outreach Centers (UOCs) at local universities are often able to assist school counselors in fulfilling components of the school counseling programs implemented in their districts. The American School Counseling Association (ASCA) model recommends that school counselors collect and analyze the data. The School Counselor Professional Standards and Competencies (ASCA, 2019, p. 5), direct school counselors to "demonstrate understanding of ...research" (B-PF), "use education research to inform decisions and programming" (B-PF2.h) and "share strategies that support student achievement with families, teacher, administrators, school staff and community organizations" (B-SS5.b). This often entails a substantial amount of work for school counselors - particularly requiring working knowledge of research skills that are often utilized infrequently. While graduate programs instruct school counseling candidates on research, data collection and program construction, UOCs may be able to provide additional assistance through the development of assessments, aggregation of data, and understanding gaps in service. UOCs can assist with the data collection, aggregation, and interpretation, thereby creating time for school counselors to directly impact students immediate issues. School counselors will then be able to use the data reports created by the UOC to show the direct impact of the school counseling direct services. Program assessment data are extremely helpful when requesting funding from public or private foundations, grant agencies, and/or community members. UOCs are able to compile the program assessment results into reports that school counselors can utilize as marketing tools to promote comprehensive school counseling programs. This enables school 
administrators, boards of education, community members, community partners, parents, and students to have an understanding of the efforts and programs implemented within a particular school. Longitudinal reports are able to capture the impacts and growth over time, allowing for potential funders and districts to see the quality of programming and care for students. Additionally, longitudinal data will provide the opportunity for school counselors and administrators to track academic, social/emotional, career, and/or behavioral trends.

University Outreach Centers (UOCs) can also assist school counselors with program delivery within specific areas. While the expectation is for school counselors to deliver comprehensive school programming, school counselors often struggle to create enough programming available to all students while meeting the diverse needs of the student population. Furthermore, student and family issues often exceed school counselors' available time, skill level and/or scope of practice for a school counselor. UOCs can offer to link school counselors to other community partners that have related professionals who are available to provide additional programming for classroom guidance, small groups, or school-wide psychoeducation. School counselors may receive small discretionary budgets from their school administrator to hire professionals to deliver programs, order supplies, or assist with data management. However, the funds allocated are often insufficient and rarely cover the expenses that are desired for the entire school year. UOCs can assist with funding opportunities by partnering with school counselors to co-author grants (e.g., federal, state, local), develop budgets, and provide program evaluation. School counselors could establish goals with UOCs to secure funding at their school to expand services, develop 
new programs initiatives, and obtain resources leading to opportunities for students and families.

\section{Resource Analysis}

The role of school counselors has changed considerably since the inception of the school counseling profession in the mid $-20^{\text {th }}$ century. School counselors are expected to obtain more education (e.g., 60 semester hours effective July 1, 2020 (CACREP, 2016)), including a master's degree that focuses on how school counselors can provide an environment that promotes the likelihood of student success in the future. School counselors are responsible for many roles within a school district, and must develop unique skill sets to support every student in their school. The American School Counseling Association (ASCA) recommends the implementation of a comprehensive school counseling model to provide high quality programs for all students. Because school counselors are charged with numerous duties throughout the school building, it is imperative for them to conduct a self- assessment. This activity should evaluate the skills, expected duties, and needs of the school counselor. Once the assessment activity is complete, school counselors can identify skill deficits and areas for professional growth in order to have greater impact through their comprehensive school counseling program. Additionally, school counselors should identify community partners that can fill voids in programming and services for students and families.

Resource development (e.g., operational budgets, discretionary funding, grant writing, budget development, budget management) are topics that may be discussed, but 
often are not covered in depth in graduate school counseling programs. An initial question asked by a school counselor is where should they go to begin a collaborative community partnership. Outside organizations may have an interest in working with the school counselor, but there may not be sufficient human or fiscal resources to start a true collaborative relationship. Unless a school counselor worked in a particular community, they may not be familiar with all the community and resources available. Initiating a community map of services, agencies, and places of referral is important for school counselors to determine whom to ask for resources. Unfortunately, school counselors rarely have time to create a detailed community map and then build relationships with each community organizations. In addition, community agencies can have challenges understanding the school environment and how to support comprehensive school counseling programs. A University Outreach Center at a local university can be a helpful place to start for a school counselor.

\section{Process for School Counselor-University Outreach Center (UOC) Connection}

School counselors interested in creating a relationship with a University Outreach Center (UOC) should consider the following steps: 1) reflect on the counseling needs of their students (i.e., resources, materials, services, funding); 2) contact a local university to inquire if they have a UOC and schedule a time to discuss needs; 3) determine a shared reason to collaborate and outline the expectations of the school counselor and UOC; and 4) keep the all partners involved apprised of the collaboration progress.

The process for a successful School Counselor - University Outreach Center (UOC) connection begins with the school counselor reflecting on the following questions: What services do your students need (e.g., academic, career, personal/social, mental health, 
enrichment, etc.)? What additional resources do you need to increase the effectiveness of your school counseling program? Resource needs may include materials (e.g., equipment, incentives, consumables, educational materials), programming (e.g., after-school, inschool, one-time speaker, clubs), research (e.g., data collection, demonstrating areas of need, effectiveness), and collaborations (e.g., grant writer, evaluator). What technical tasks do you need assistance accomplishing (e.g., writing a grant, managing a grant, conducting a program evaluation of a grant)? Finally, what funding opportunities (e.g., grants, community foundations, etc.) are available that could offer support to school counseling program?

Once a school counselor has completed some preliminary work, they should contact a University Outreach Center at their local university. A school counselor can find a UOC by doing a web search of departments / centers at their university or by calling the university and explaining the type of service department for which they are seeking. If a local university does not have a center providing those types of services, then a school counselor can expand their search to other universities within their region. Although it is convenient to work with a UOC within your area, it is not unusual for UOCs to work with school counselors outside their local area.

Once a UOC is identified, a school counselor should request a meeting with the Director of the Center regarding a potential collaboration. A school counselor can offer to meet at the university or invite the director of the UOC to meet at their school. It can be helpful for the school counselor to share the answers to the reflection questions above to determine if there is mutual interest in moving forward in the collaboration. If not, inquire from the UOC Director for referrals to other centers or organizations that might be 
interested in working with the school counselor on their project. If the UOC Director is interested in collaborating, then the school counselor can begin to discuss the specifics of the partnership. The UOC may have a standard Memo of Understanding (MOU) that they may ask to have the school counselor review and sign. The MOU may include information regarding the UOC fees charged to a grant if/when it one received to cover the cost of services. To avoid confusion later in the process, it is important to negotiate and document the role expectations; who is responsible for each area within the collaboration (e.g., grant writer, project manager, program evaluator, etc.). Throughout this process, it is important for the school counselor to keep their supervisor and educational administrator (i.e., principal, superintendent) apprised of the potential collaboration and have their educational administrator review, approve, and sign the MOU prior to beginning the project with the UOC.

\section{Case Example}

The following is a case example of a partnership between a University Outreach Center (UOC) at a mid-western university and a local K-12 school that focused on enhancing school counseling services. During a county school counselors meeting, a school counselor learned of the University Outreach Center (UOC) at the local university that was working with other school districts. Specifically, the school counselor was informed that the UOC was assisting with grant writing to obtain funds to operate after-school programs that focused on academic, social/emotional, and career and college readiness needs of students. The school counselor spoke with her colleagues to understand better the UOC 
and school collaboration that resulted in the school receiving funds to operate an afterschool program. Upon returning to the school, the school counselor spoke to their building principal to discuss the possibility of collaboration with the UOC. The principal suggested the school counselor contact the UOC. The school counselor gathered a list of questions and ideas to communicate the vision of her desire to increase opportunities for students to have greater access to academic, social/emotional, behavioral, and career supports. The school counselor collected various data points within the school building that highlighted the areas of student need. The school counselor identified an increase in student appointments regarding social/emotional issues (e.g., visits to school counselor's office, requests for classroom guidance lessons and groups from teachers), and behavioral issues (e.g., visits to the principal's office, disciplinary referrals), as well as academic deficiencies through school data (e.g., report cards, state test scores, number of mid-term reports sent to parents, etc.). The district administrators wanted to increase the career and college readiness of their students. However, the school counselor realized she was not providing necessary comprehensive school counseling services, as the data indicated her focus was primarily focused on the students' social/emotional and behavioral issues.

With permission from her school principal, the school counselor arranged a meeting with the UOC to discuss grant opportunities to address the lack of resources within her school building. The UOC scheduled a time to meet with the school counselor and the principal to discuss the services and opportunities for collaboration. During the meeting, the school counselor and principal discussed academic, social/emotional, behavioral, and career needs of the students. Examples of needs discussed included: academic issues (i.e., consistently low statewide test scores, increased number of students requiring and IEP/504); 
social/emotional issues (i.e., increased number of referrals to community counseling agency, increased number of relational issues reported within the building, increased number of visits to the school counselor's office, increased problems at home, increased requests from teachers for classroom guidance lessons); behavioral issues (i.e., increasing absenteeism with certain populations within the building, increased visits to the principal's office, increased incidents of classroom disruption); and career issues (i.e., reduced interest expressed by students during career fairs, lack of applicable information for students from career inventories). The UOC identified a specific grant that could serve as a potential funding source, address the needs of the school building, and meet the timeline identified by the principal and school counselor. During meeting the UOC, school counselor, and principal created a plan to develop a grant proposal and assigned tasks and expectations to ensure the fulfillment of responsibilities and requirements. Finally, there was a discussion of retention of services for the UOC. The UOC discussed various options (e.g., paying for grant writing services for the UOC through district funds, agreeing to reduced grant writing rate as a condition of including cost to the UOC within the grant, or contracting with the UOC to operate as the fiscal agent of the grant in collaboration with the district without charging a grant writing fee). Due to the UOCs experience writing grants, the district asked the UOC to write the after-school grant application as the fiscal agent in collaboration with the school district. Since the UOC relies on grant funds and contracts to operate, this allowed the UOC to receive the funding necessary to operate, but also allowed the district to utilize the services without paying existing funds out of the district budget.

During the writing of the funding application, the school counselor and the UOC were met regularly. The meetings covered various aspects of the funding application and 
provided the UOC the details needed to develop the grant proposal. Items discussed included the needs of the students, design of the programming, student recruitment and retention to the program, parent involvement in the program, fiscal parameters, and the role of the district, school counselor, and UOC upon the award of the grant. These conversations were necessary to design a program and grant application that met funding application requirements, and outlined the needs of the school and funded services provided by the UOC. The school counselor communicated this information and advocated to her administration for resources needed to contribute for a successful application and partnership with the UOC. The resources provided by the school included physical space, custodial services, busing services, access to student data for grant compliance, cafeteria services, and an invitation to building leadership team meetings to connect after-school program services with current issues and needs of teachers and students. Services provided by UOC included program management, grant compliance, and fiscal management. Finally, during the planning period, the school counselor was able to gather relevant data from the school district. The UOC also used the data collected through the district school counseling program. The information was critical to include within the grant application as it provided an accurate representation of the needs of students.

Once the after-school grant award was received, the UOC and the school counselor worked together to inform faculty, staff, parents, students, and community members. The school counselor and UOC agreed that they would work together in identifying potential individuals to employ in the after-school program. This collaboration allowed for a selection of an effective leader to work within the school building and the UOC. Continuous communication between the school counselor and UOC ensured that 
programming was developed to align with the needs of potential student participants. Regularly scheduled meetings were held to discuss program development, student recruitment and retention, family engagement, and data collection. The school counseling program data was the primary factor that contributed to the programmatic decisions in the after-school program and the daily school counseling program. Communication and data sharing contributed to the development of appropriate programs and resource attainment. Additionally, as issues arose with students and families, the UOC and school counselor were able to collaborate regarding how to address those concerns to ensure students were able to meet program objectives.

A highlight of the partnership was the connection to the research initiatives conducted by the university faculty through the UOC. The programming provided through the grant award assisted the students in gaining academic, social/emotional, behavioral, and career access. However, the UOC was able to link university faculty to opportunities for research initiatives within the after-school programming. These initiatives included, but were not limited to, small group interventions for reading and math, field experience opportunities for pre-service teachers allowing for smaller ratios, youth development lessons (e.g., nutrition, social/emotional, and wellness lessons), and family trainings focused on parenting and communication skills. These opportunities enabled the lowest performing students, and their families, the opportunities to receive additional academic, social/emotional, behavioral, and career supports while gathering data to show the positive impact of the additional supports.

As the multi-year grant continued, the collaboration between the school counselor, administration, and UOC continued to strengthen. Other funding opportunities have been 
identified and the UOC has been able to provide grant writing assistance and advisement. As collaboration, resources, and funding opportunities are available, the UOC is able to share those opportunities with the school counselor to strengthen the school counseling program and increase resources to the students and families within the school building.

\section{Discussion}

While there are many benefits to the school - university partnership, DiSibio and Gable (1997), cautioned that difficulties often arise when there are lack of incentives for both sides to make the partnership continue long-term. For example, if there are significant benefits to a school district to have a grant written for them, but little or no incentive for a UOC to write the grant then it is unlikely there will be a successful collaboration. Additionally, challenges can include 'turf' issues - meaning participants try to control issues that they perceive their own and block others from exerting influence within their area. This is particularly pronounced when there is a lack of agreement regarding which participant (i.e., UOC, school counselor, external contracted service, etc.) is responsible for an aspect of a project. Individuals who are distrustful and lack respect for the expertise of other professionals can often contribute to problematic relationship issues (DiSibio \& Gamble, 1997).

There are several considerations when working with students, data, and outside organizations. When working with outside organizations, one of the most significant legal implications is ensuring the higher educational institution's university outreach center (UOC) has a clear understand of the Family Educational Rights and Privacy Act (FERPA) 
as it relates to students within a K-12 school. It is imperative that there is a Memorandum of Understanding (MOU) outlining the procedures to protect the K-12 students' personal information and comply with federal regulations. The information collected at K-12 school sites and shared with the UOC will be student data. It is important to inform and obtain permission from parents indicating a third party (i.e., UOC, university faculty, etc.) will be working with the school counselor to analyze data on their children. Parents should be allowed the opportunity to meet UOC staff if this would help them better understand the process. Often, UOCs have access to evidence based interventions and innovative approaches to working with children based upon the research by faculty within their institution. In situations where school counselors are working with UOCs, there may be the opportunity to connect to research opportunities through faculty providing innovative counseling interventions, classroom guidance lesson with students, and/or piloting school counseling programs focusing on academic, behavioral, or social/emotional development. It is important that school counselors and UOCs examine the ethical implications of involving students engaged in research. The school counselor must consider the inclusion and support of school administration, while the UOC and faculty researchers must consider the inclusion and approval of the university Institutional Research Board. School counselors and UOCs should also have a thorough understanding of the limitations (e.g., financial, student/family participation, etc.) of the school district.

When examining legal and ethical issues, conversations between the school counselor and the UOC must focus on the ability to effectively support the school counselors without harming the students or creating additional liability for the school counselor. Legal concerns can occur when grant funding is a factor. It is importance for 
the UOC and school counselor to be aware of the stipulations, outlined by the funding agency, on the spending limitations and how items purchased with grant funds are to be utilized. Ethical considerations for school counselors are outlined in the ASCA Ethical Standards (2016). ASCA ethical standard A.6.f directs school counselors to "attempt to establish a collaborative relationship with outside service providers to best serve students. Request a release of information signed by the student and/or parents/guardians before attempting to collaborate with the student's external provider" (p. 4). Additionally, ASCA ethical standard A.10, encourages school counselors to focus on providing services for underserved and at-risk Populations, while ASCA ethical standard A.10.c encourages school counselors to identify resources needed to enhance the student's education.

There has been little research on the utilization or impact of UOCs on comprehensive school counseling programs. An opportunity for future research includes examining the effects of the collaboration between school counselors and UOCs on expanding comprehensive school counseling program services. A study could examine how UOCs are able to assist school counselors developing community relationships that expand programming within the school building. An additional opportunity for research could also focus on the UOCs ability to assist the school counselor with data collection. This includes not only analyzing the data collected, but also involves working with the school counselor to identify what data needs collected. This process would enable the school counselor to collect information about students within their school counseling program that may previously been missed. Data collection is also crucial to celebrating positive outcomes attributed to the school counselor, thus further establishing a need for additional comprehensive school counseling program services. 
School counselors need significant resources and university outreach centers (UOCs) can provide grant writing and management, program development, needs assessment, program evaluation, and professional development. UOCs mission is to connect with community partners on projects where there are shared interests and benefits to stakeholders. Through these community partnerships, school counselors can access resources to address the needs of students and improve their comprehensive school counseling programs. 


\section{References}

American School Counselor Association (2019). ASCA School Counselor Professional Standards \& Competencies. Alexandria, VA: Author.

American School Counselor Association (2016). ASCA Ethical Standards for School Counselors. Alexandria, VA: Author.

Atici, M. (2014). Examination of school counselors' activities: From the perspectives of counselor efficacy and collaboration with school staff. Educational Sciences Theory and Practice, 14(6), 2107-2119. doi: 10.12738/estp.2014.6.2554

Buisson, G. J., \& Salgo, J. (2012). College collaboration with gifted programs: Deaf studies unit (Part 2). American Annals Of The Deaf, 157(2), 87-91. doi:10.1353/aad.2012.1618

Bryan, J., \& Holcomb-McCoy, C. (2007). An examination of school counselor involvement in school-family-community partnerships. Professional School Counseling, 10(5), 441-454.

Castro-Atwater, S. (2013). Establishing a SUCCESS-ful school counseling program through university-community collaboration. Journal Of Instructional Psychology, 40(1-4), 91-97.

Council for Accreditation of Counseling and Related Educational Programs (2015). 2016 CACREP Standards. Retrieved from https://www.cacrep.org/for-programs/2016cacrep-standards/ 
Cobia, D. C., \& Henderson, D. A. (2007). Developing an effective and accountable school counseling program (2nd ed.). Upper Saddle River, NJ: Pearson Education, Inc.

Di Sibio, R. A., \& Gamble, R. J. (1997). Collaboration between schools and higher education: The key to success. College Student Journal, 31(4), 532-536.

Fleisher, B. M., Westfield, E. A., \& Bank, J. L. (1990). Raising literacy levels: A college/community agency/public school partnership. Academic Therapy, 25(5), $635-644$.

Grineski, S. (2003). A university and community-based partnership: After-school mentoring for low-income youth. The School Community Journal, 13(1), 101114.

Kreulen, G. J., Bednarz, P. K., Wehrwein, T., \& Davis, J. (2008). Clinical education partnership: A model for school district and college of nursing collaboration. The Journal Of School Nursing, 24(6), 360-369. doi:10.1177/1059840508325429

Mahoney, J. L., Levine, M. D., \& Hinga, B. (2010). The development of after-school program educators through university-community partnerships. Applied Developmental Science, 14(2), 89-105, doi: 10.1080/10888691003704717

Mellin, E. A., Belknap, E. E., Brodie, I. L, \& Sholes, K. (2015). Opening school doors to communities and families: A social capital perspective for multiparty collaboration. Journal for Social Action in Counseling and Psychology, 7(1), 118. doi: $10.12738 / \operatorname{estp} 32014.6 .2554$

Stone, C., \& Dahir, C. A. (2006). The transformed school counselor. Boston, MA: Houston Mifflin Co. 
Walsh, M. E., Howard, K. A., \& Buckley, M. A. (1999). School counselors in schoolcommunity partnerships: Opportunities and challenges. Professional School Counseling, 2(5), 349-357.

Wright, R. J. (2012). Introduction to school counseling. Thousand Oaks, CA: Sage. 